\title{
Cancer mortality inequalities in urban areas: a Bayesian small area analysis in Spanish cities
}

\author{
Rosa Puigpinós-Riera ${ }^{1,2,3^{*}}$, Marc Marí-Dell'Olmo ${ }^{2,1}$, Mercè Gotsens ${ }^{2,1}$, Carme Borrell ${ }^{1,2,4}$, Gemma Serral ${ }^{1,2}$, \\ Carlos Ascaso ${ }^{3}$, Montse Calvo ${ }^{5}$, Antonio Daponte ${ }^{2,6}$, Felicitas M Domínguez-Berjón ${ }^{7}$, Santiago Esnaola ${ }^{5}$, \\ Ana Gandarillas ${ }^{8}$, Gonzalo López-Abente 9 , Carmen M Martos ${ }^{10,11}$, Miguel A Martínez-Beneito ${ }^{10}$, \\ Agustín Montes-Martínez ${ }^{2,12}$, Imanol Montoya ${ }^{5}$, Andreu Nolasco ${ }^{13}$, Isabel M Pasarín ${ }^{1,2,4}$, Maica Rodríguez-Sanz ${ }^{1,2}$, \\ Marc Sáez ${ }^{2,14}$, Pablo Sánchez-Villegas ${ }^{6}$
}

\begin{abstract}
Background: Intra-urban inequalities in mortality have been infrequently analysed in European contexts. The aim of the present study was to analyse patterns of cancer mortality and their relationship with socioeconomic deprivation in small areas in 11 Spanish cities.

Methods: It is a cross-sectional ecological design using mortality data (years 1996-2003). Units of analysis were the census tracts. A deprivation index was calculated for each census tract. In order to control the variability in estimating the risk of dying we used Bayesian models. We present the RR of the census tract with the highest deprivation vs. the census tract with the lowest deprivation.

Results: In the case of men, socioeconomic inequalities are observed in total cancer mortality in all cities, except in Castellon, Cordoba and Vigo, while Barcelona ( $R R=1.5395 \% \mathrm{Cl} 1.42-1.67)$, Madrid $(\mathrm{RR}=1.5795 \% \mathrm{Cl} 1.49-1.65)$ and

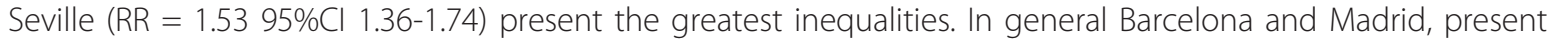
inequalities for most types of cancer. Among women for total cancer mortality, inequalities have only been found in Barcelona and Zaragoza. The excess number of cancer deaths due to socioeconomic deprivation was 16,413 for men and 1,142 for women.

Conclusion: This study has analysed inequalities in cancer mortality in small areas of cities in Spain, not only relating this mortality with socioeconomic deprivation, but also calculating the excess mortality which may be attributed to such deprivation. This knowledge is particularly useful to determine which geographical areas in each city need intersectorial policies in order to promote a healthy environment.
\end{abstract}

\section{Introduction}

Cancer has been considered a modern disease [1] due to its being linked with an increase in life expectancy. According to the study "The Global Burden of Diseases", 58.8 million people died during 2004, death being due to cancer in one eighth of them. It has been estimated that in 2008 there were 12.4 million new cancer cases, the majority of them in the Continent of America, West Pacific and Europe [2]. In Spain, cancer accounts for about a quarter of all deaths, e.g. $26.5 \%$ of

\footnotetext{
* Correspondence: rpuigpi@aspb.cat

'Servei de Sistemes d'Informació Sanitaria, Agència de Salut Pública de Barcelona, Barcelona, Spain

Full list of author information is available at the end of the article
}

all deaths in 2006 [3]. Despite the rise in incidence, cancer mortality is tending to decline in the European Union as a whole [4,5], as well as in Spain [3], something which has been attributed to early diagnosis and increased efficacy of treatments. In contrast, a rise has been detected in inequalities, both in between socioeconomic groups, and between countries and geographical areas [6-9].

Mortality observed in the population is influenced not only by individual-based factors or determinants, but also by contextual ones related to the environment in which one has lived [10]. These determinants are territorially unequally distributed generating unequal living conditions which end up affecting people's health. For

\section{() Biomed Central}


this reason it is important to ascertain, through appropriate conceptual models, the population determinants of health, and the determinants of health inequalities [11]. In this sense, the political tradition and redistributive policies of countries are related with health and with mortality $[12,13]$. Spain is a country whose recent history presents a broad spectrum of sociopolitical change. In the recently inaugurated XXI century, an important part of this country's current population was born during a dictatorship, and lived through the political transition which led to the present modern democracy, with a health system providing universal coverage, and, among other changes, the country has evolved from being a country of emigrants to become a country which in the last decade has experienced an unprecedented, exponential rise in immigration [14]. All these political changes have involved changes in people's living conditions, and hence the importance of studying the inequalities experienced, while taking account of the environment.

Half of the world's population currently lives in large cities [15] and it is estimated that by 2030 the figure will reach $60 \%$ or more. Urbanization is usually linked with a country's economic growth and determines important changes in citizens' lifestyles, but does not necessarily imply improvement. Socioeconomic inequalities in health tend to be larger in urban areas with deprived and poor populations being concentrated in marginalized neighbourhoods and urban slums located at the centre or peripheral areas of these cities [16]. However, intra-urban inequalities in mortality have been infrequently analysed in European contexts. In recent years some studies have been conducted in Spanish cities which show a relationship between the socioeconomic deprivation of the geographical area of residence, and mortality [17-19]. But these studies have not focused on analysing inequalities in cancer mortality from a social and environmental perspective [20]. Thus, the aim of the present study was to analyse patterns of cancer mortality and their relationship with socioeconomic deprivation in small areas in 11 Spanish cities.

\section{Methods}

\section{Design}

Spain is located in southern Europe, and with more than 46 million inhabitants, is the fifth most populous country in the European Union. Administratively and politically it is organized into 17 autonomous communities, plus Ceuta and Melilla as autonomous cities.

This study was carried out in the framework of a project known as MEDEA (Socioeconomic and environmental inequalities in mortality in small areas of Spanish cities - http://www.proyectomedea.org/) conducted jointly by 10 Spanish research groups. The methodology of this study has been described elsewhere [21], we here explain only the main aspects. The study uses a cross-sectional ecological design whose goal is to analyse mortality inequalities at the small area level in Spanish cities. Units of analysis were the census tracts of the eleven largest cities included in the study according to the 2001 Population and Households Census. These cities included 20.5\% of the Spanish population in 2001 and are located in a variety of regions (Autonomous Communities) of Spain, from the wealthiest to the poorest: Catalonia (Barcelona), Comunidad de Madrid (Madrid), Euskadi (Bilbao), Aragón (Zaragoza), Comunitat Valenciana (Alicante, Castellón and Valencia), Galicia (Vigo), Andalucía (Córdoba, Málaga, Sevilla).

\section{Study population and information sources}

The study population consisted of people residing in the cities during the period 1996 to 2003. Mortality data were obtained through the mortality registries of the Autonomous Communities or from the mortality registry of the city in the case of Barcelona.

The expected numbers of deaths in each census tract were calculated taking as reference the mortality rates by sex, age (5 year age mortality rates) and leading cause of death for Spain, year 2001, provided by the National Institute of Statistics (Instituto Nacional de Estadística). In order to elaborate an index of deprivation the source of data was the 2001 Population and Household Census. The Population and Household Census was also used to obtain information about the number of inhabitants stratified by sex, age (in five-year groups) and census tract.

\section{Mortality data}

Number of deaths by five-year age group, sex, census tract of residence, and the underlying cancer cause of death were extracted from mortality registries. The census tract was obtained through the postal address of the deceased provided by either the Death Certificate or by the Local Census. Due to technical problems in geocoding place of residence, some deaths could not be geographically referenced, the proportions varying from $0.13 \%$ in Bilbao to $14.28 \%$ in Vigo. Except for Vigo, these percentages were always lower than $7 \%$. Underlying cancer causes of death were coded using the International Classification of Diseases: $9^{\text {th }}$ revision (ICD-9) for deaths occurring between 1996 and 1998, and $10^{\text {th }}$ revision (ICD-10) for those occurring between 1999 and 2003. The groups of causes of cancer mortality studied and their ICD codes are shown in table 1.

\section{Socioeconomic deprivation index}

A deprivation index was calculated for each census tract using the methodology proposed by Dominguez-Berjon 
Table 1 Population (number of inhabitants and census tract quartile distribution), number of census tracts and number of deaths by cause of cancer death

\begin{tabular}{|c|c|c|c|c|c|c|c|c|c|c|c|c|c|}
\hline & $\begin{array}{c}\text { ICD- } \\
10\end{array}$ & $\begin{array}{l}\text { ICD- } \\
9\end{array}$ & Alicante & Barcelona & Bilbao & Castellón & Córdoba & Madrid & Málaga & Sevilla & Valencia & Vigo & $\overline{\text { Zaragoza }}$ \\
\hline \multicolumn{14}{|l|}{ Population } \\
\hline $\begin{array}{l}\text { Number of } \\
\text { inhab }\end{array}$ & & & 284,580 & $1,503,884$ & 349,972 & 147,667 & 308,072 & $2,938,723$ & 524,414 & 684,633 & 738,441 & 280,186 & 614,905 \\
\hline \multicolumn{14}{|l|}{$\begin{array}{l}\text { Quartiles in } \\
\text { census tracts }\end{array}$} \\
\hline$P_{25}$ & & & 931.25 & 746.00 & 895.00 & 1092.00 & 1053.50 & 952.00 & 962.25 & 990.25 & 862.25 & 962.00 & 1028.00 \\
\hline$P_{50}$ & & & 1129.00 & 923.00 & 1188.50 & 1457.00 & 1330.50 & 1169.50 & 1180.50 & 1253.00 & 1135.00 & 1174.00 & 1276.50 \\
\hline$P_{75}$ & & & 1336.75 & 1166.00 & 1493.75 & 1770.50 & 1621.25 & 1442.00 & 1457.00 & 1612.75 & 1460.50 & 1404.50 & 1566.00 \\
\hline $\begin{array}{l}\text { Number of } \\
\text { census tracts }\end{array}$ & & & 222 & 1491 & 288 & 95 & 224 & 2358 & 422 & 510 & 598 & 236 & 462 \\
\hline \multicolumn{14}{|l|}{$\begin{array}{l}\text { Causes of death } \\
\text { in men }\end{array}$} \\
\hline Stomach & $\mathrm{C} 16$ & 151 & 179 & 1051 & 353 & 101 & 140 & 2160 & 231 & 352 & 478 & 214 & 425 \\
\hline Colon & $\mathrm{C} 18$ & 153 & 259 & 1950 & 468 & 123 & 244 & 3116 & 315 & 659 & 781 & 240 & 583 \\
\hline Rectum & $\begin{array}{l}\text { C19- } \\
\text { C21 }\end{array}$ & 154 & 90 & 624 & 174 & 55 & 60 & 1082 & 99 & 162 & 258 & 86 & 287 \\
\hline Larynx & $\mathrm{C} 32$ & 161 & 69 & 522 & 209 & 54 & 99 & 989 & 148 & 224 & 228 & 59 & 211 \\
\hline Lung & $\begin{array}{l}\text { C33- } \\
\text { C34 }\end{array}$ & 162 & 882 & 5896 & 1282 & 447 & 805 & 9381 & 1335 & 2054 & 2513 & 722 & 2077 \\
\hline Prostate & C61 & 185 & 246 & 1864 & 465 & 178 & 197 & 3253 & 342 & 506 & 861 & 291 & 711 \\
\hline Bladder & $\mathrm{C} 67$ & 188 & 198 & 1228 & 266 & 86 & 189 & 1905 & 231 & 471 & 575 & 131 & 434 \\
\hline Hematologic & $\begin{array}{l}\text { C81- } \\
\text { C96 }\end{array}$ & $\begin{array}{l}200- \\
208\end{array}$ & 191 & 1471 & 282 & 90 & 197 & 2193 & 250 & 440 & 532 & 167 & 479 \\
\hline Total cancer* & & & 3086 & 21493 & 5270 & 1576 & 2883 & 36417 & 4370 & 7106 & 9189 & 2937 & 7454 \\
\hline \multicolumn{14}{|l|}{$\begin{array}{l}\text { Causes of death } \\
\text { in women }\end{array}$} \\
\hline Stomach & $\mathrm{C} 16$ & 151 & 104 & 813 & 206 & 64 & 86 & 1536 & 116 & 224 & 300 & 153 & 310 \\
\hline Colon & $\mathrm{C} 18$ & 153 & 237 & 1776 & 344 & 135 & 196 & 2678 & 303 & 596 & 687 & 190 & 495 \\
\hline Rectum & $\begin{array}{l}\text { C19- } \\
\text { C21 }\end{array}$ & 154 & 71 & 517 & 104 & 32 & 45 & 792 & 76 & 128 & 202 & 70 & 161 \\
\hline Lung & $\begin{array}{l}\text { C33- } \\
\text { C34 }\end{array}$ & 162 & 132 & 977 & 225 & 52 & 82 & 1533 & 146 & 216 & 339 & 116 & 249 \\
\hline Breast & $\mathrm{C} 50$ & 174 & 327 & 2539 & 525 & 136 & 316 & 3972 & 479 & 849 & 1036 & 280 & 797 \\
\hline Bladder & $\mathrm{C} 67$ & 188 & 46 & 327 & 60 & 19 & 35 & 452 & 62 & 76 & 92 & 39 & 96 \\
\hline Hematologic & $\begin{array}{l}\text { C81- } \\
\text { C96 }\end{array}$ & $\begin{array}{l}200- \\
208\end{array}$ & 165 & 1449 & 269 & 65 & 179 & 2109 & 254 & 433 & 509 & 175 & 409 \\
\hline Total cancer* & & & 1906 & 14842 & 3241 & 883 & 1777 & 24380 & 2768 & 4737 & 5899 & 1919 & 4649 \\
\hline
\end{tabular}

Men and women, 11 cities of Spain, 1996-2003.

*All cancers, i.e. not just the types of cancer presented in the table.

et al [22] (principal component analysis) based on the socioeconomic indicators available for each census tract. Five simple indicators were included in this index (year 2001): a) Unemployment; b) Low educational level; c) Low educational level in young people (16-29 years); d) Manual workers; and e) Temporary workers. The index is normalized with a mean of 0 and standard deviation of 1 , and the higher the index the higher the socioeconomic deprivation.

\section{Data analysis}

It was assumed that the observed deaths for each census tract follow a Poisson distribution. In order to control the variability in estimating the risk or the Standardized Mortality Ratio (SMR), which is the ratio of observed and expected deaths in each census tract, we used Bayesian models, and more specifically the model proposed by Besag, York and Mollie (BYM) [23] which takes into account two types of random effects: spatial and 
heterogeneous. Prior distributions are assigned to the random effects, and hyper prior distributions to the parameters of the prior distributions. In this study, for the spatial effect, a conditional autoregressive normal distribution (CARN) was chosen. Following the suggestion made by several authors [24-26] a uniform distribution $U(0,5)$ is assigned to the standard deviation of the random effects. In the model, the deprivation index was introduced as a quantitative variable.

As the scale of the deprivation index is adimensional, to illustrate the impact of deprivation on mortality we present, for every cancer cause of death and city, the Relative Risk (RR) of the census tract with percentile 95 of the deprivation index (highest deprivation) vs. the census tract with percentile 5 (lowest deprivation). This indicator can be considered a trimmed measure of the inequalities arising from deprivation for every city and cause, as it compares both ends of the scale and has been trimmed (to 5 and 95 percentiles) to make it more robust.

The estimations of RR were assessed through the mean of the posterior distribution and its 95\% Credibility Interval (95\%CI). This distribution was obtained using Monte Carlo methods based on Markov chains (MCMC), as implemented in the WINBUGS program, version 1.4.3 [27] and which was called from $R$ 2.3.1 [28]. Model convergence was assessed using the $R$-hat statistic (Brooks-Gelman-Rubin statistic in WINBUGS) and effective sample size of the chains (n.eff statistic in R) [29]. Criteria for convergence were: $R$-hat less than 1.1 and n.eff greater than 100 for all the parameters summarized by the model.

In order to obtain the excess number of deaths related with socioeconomic deprivation we calculated the excess of deaths in each census tract comparing observed and expected deaths under the assumption that the deprivation of each area was the same as the average deprivation of the $10 \%$ of areas with the lowest deprivation $[30,21]$. The total excess of deaths was obtained by summing the excess deaths across all census tracts. We have also obtained the percentage of excess of deaths with respect to the total observed deaths. For each measure we have calculated its posterior mean and $95 \%$ posterior credibility interval.

All analyses were conducted separately for each city and for men and women [31]. The geographical distributions of smoothed SMR values derived from the BYM models are displayed using maps of septiles. The deprivation index is also displayed using a septile-based map. All maps were plotted using the $\mathrm{R}$ statistical package. All maps are presented in green and brown colours. Green colours show areas with lowest risk of mortality or lowest deprivation while brown colours show just the opposite.

\section{Results}

Table 1 presents the number of inhabitants, according to the 2001 census, of each of the 11 cities included in the study, along with the number of census tracts into which it is divided, varying from 95 in Castellón with 147,667 inhabitants to the 2358 census tracts of Madrid, with nearly 3 million inhabitants. Considering all the cities, seventy-five percent of census tracts have populations of at most from 1166 people (Barcelona) to 1770 (Castellón). Finally, it also presents the number of deaths for the different types of cancer studied, the most common being lung, colon and prostate cancers among men, and breast, colon and lung cancers among women. Almost all the cities present the same pattern.

Table 2 and 3 show the associations between mortality and socio-economic deprivation for men and women respectively. Table 4 shows the excess of deaths due to socio-economic deprivation in both cases.

\section{Cancer mortality inequalities in men}

In the case of men (table 2), socioeconomic inequalities are observed in total cancer mortality in all cities, except in Castellón, Córdoba and Vigo, while Barcelona ( $R R=$ 1.53 95\%CI 1.42-1.67), Madrid ( $R R=1.57$ 95\%CI 1.49 $1.65)$ and Sevilla $(R R=1.5395 \%$ CI 1.36-1.74) present the greatest inequalities. The proportion of deaths due to cancer in these cities which may be attributed to socioeconomic deprivation (excess of deaths) would be, respectively, $17.38 \%, 19.49 \%$ and $16.31 \%$. The excess number of cancer deaths due to socioeconomic deprivation was 16,413 (table 4). Figure 1 and 2 present, as an example, the maps for 5 cities, three with significant inequalities (Barcelona, Madrid, Seville) and two others (Córdoba and Vigo) with no inequalities. In Cordoba and Vigo we may observe a weak relationship between areas with socioeconomic deprivation and smoothed SMR, whereas in Madrid, Barcelona and Sevilla there are clear similarities between the spatial patterns of deprivation and of risk of mortality in many census tracts, although not in all.

In terms of type of cancer, lung and larynx present significant inequalities in all cities except Castellon and Vigo, with RR values above 3 in the case of larynx cancer in cities such as Alicante, Barcelona, Bilbao, Córdoba and Sevilla, this value being higher than the RR found for lung cancer. Other types of cancer which present significant inequalities in various cities are those of stomach, followed by rectum. In general Barcelona and Madrid, the two most populous cities in the country, present inequalities for most types of cancer, in particular both cities present inequalities for stomach, rectum, larynx, and lung cancer mortality. In contrast, in the smaller cities, Vigo and Castellón, no significant inequalities are found for any type of cancer (table 2). 
Table 2 Association between mortality by cancer in men and the socioeconomic deprivation index

\begin{tabular}{|c|c|c|c|c|c|c|c|c|c|c|c|}
\hline & Alicante & Barcelona & Bilbao & Castellón & Córdoba & Madrid & Málaga & Sevilla & Valencia & Vigo & Zara \\
\hline Cause & RR 95\% Cl & RR 95\% Cl & RR 95\% Cl & RR 95\% Cl & RR 95\% Cl & RR 95\% Cl & RR 95\% Cl & RR 95\% Cl & RR 95\% Cl & R 95\% Cl & RR 95\% Cl \\
\hline Stomach & 1.95 1.63-3.08 & 1.71 1.30-2.17 & $1.73 \quad 1.22-2.38$ & $1.520 .63-2.90$ & $0.730 .35-1.35$ & 1.67 1.44-1.94 & $1.520 .93-2.41$ & $1.350 .90-1.91$ & 1.44 1.07-1.96 & $1.050 .55-1.74$ & $1.330 .96-1.83$ \\
\hline Colon & $1.280 .77-2.03$ & $1.100 .90-1.35$ & $1.180 .80-1.66$ & $1.310 .62-2.31$ & $0.880 .51-1.44$ & $1.060 .92-1.24$ & $1.010 .66-1.53$ & $0.870 .66-1.14$ & $1.060 .82-1.35$ & $0.630 .38-0.93$ & $1.230 .91-1.6$ \\
\hline Rectum & $1.580 .63-3.34$ & $1.62 \quad 1.22-2.12$ & $0.860 .45-1.42$ & $0.990 .32-2.34$ & $2.050 .61-5.08$ & $1.411 .13-1.74$ & $2.571 .23-5.04$ & $1.270 .72-2.20$ & $1.300 .81-1.96$ & $1.170 .49-2.28$ & $1.390 .88-2.05$ \\
\hline Larynx & 3.77 1.43-8.20 & $3.512 .64-4.63$ & $3.362 .10-5.09$ & $3.350 .82-9.93$ & $3.251 .51-6.18$ & $2.862 .20-3.57$ & $2.84 \quad 1.54-4.82$ & $3.792 .41-5.65$ & $1.661 .04-2.54$ & $1.440 .53-3.18$ & $2.951 .80-4$ \\
\hline ung & $1.83 \quad 1.41-2.35$ & $1.901 .66-2.15$ & $1.761 .44-2.14$ & $0.970 .65-1.37$ & $1.361 .00-1.78$ & $1.911 .73-2.09$ & $1.801 .39-2.34$ & $1.881 .54-2.26$ & $1.511 .26-1.80$ & $1.030 .71-1.43$ & 1.481 \\
\hline Prostate & 7 & 16 & 50 & 95 & 0. & 0.9 & 32 & 0.8 & 0.9 & 0.8 & 1. \\
\hline Bladder & 07 & 51 1.29-2.00 & $30.86-2.22$ & 03 0.38-2.32 & $370.72-2.28$ & $1.361 .15-1.63$ & $1.47 \quad 0.94-2.26$ & $1.410 .99-2.03$ & $1.140 .85-1.48$ & 1.43 & 1. \\
\hline 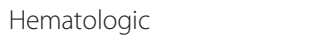 & 23 & .38 & 1.09 & $040.39-2.21$ & $0.38 \mathrm{C}$ & $1.06 \mathrm{C}$ & 0.77 & 1.020 & $0.841 .22-1.53$ & 0.920 & 0 \\
\hline & & & & & & & & & & & \\
\hline
\end{tabular}

RR comparing percentiles 5 and 95 of the deprivation index. Men, 11 cities of Spain, 1996-2003.

RR: Relative risk of mortality.

95\% Cl credibility interval.

Table 3 Association between mortality by cancer in women and the socioeconomic deprivation index

\begin{tabular}{|c|c|c|c|c|c|c|c|c|c|c|c|}
\hline & Alicante & Barcelona & Bilbao & Castellón & Córdoba & Madrid & Málaga & Sevilla & Valencia & Vigo & Zaragoza \\
\hline Causes of death in women & RR $95 \% \mathrm{Cl}$ & RR $95 \% \mathrm{Cl}$ & RR $95 \% \mathrm{Cl}$ & RR 95\% Cl & $\mathrm{RR} 95 \% \mathrm{Cl}$ & RR $95 \% \mathrm{Cl}$ & $\mathrm{RR} 95 \% \mathrm{Cl}$ & RR $95 \% \mathrm{Cl}$ & RR 95\% Cl & RR 95\% Cl & RR 95\% Cl \\
\hline Stomach & $0.680 .26-1.44$ & $1.741 .34-2.20$ & $1.560 .82-2.61$ & $1.250 .45-2.69$ & $1.000 .41-2.04$ & $1.511 .26-1.77$ & $1.260 .54-2.37$ & $1.140 .70-1.74$ & $1.711 .11-2.54$ & $0.920 .46-1.57$ & $1.250 .85-1.76$ \\
\hline Colon & $1.060 .59-1.76$ & $1.000 .84-1.18$ & $0.850 .54-1.25$ & $0.940 .45-1.67$ & $0.480 .24-0.84$ & $0.870 .75-0.99$ & $1.050 .67-1.57$ & $0.940 .69-1.25$ & $1.130 .83-1.46$ & $0.590 .35-0.96$ & $0.980 .71-1.28$ \\
\hline Rectum & $1.590 .62-3.46$ & $1.300 .92-1.79$ & $1.200 .54-2.27$ & $0.450 .07-1.52$ & $1.160 .24-3.02$ & $1.300 .96-1.69$ & $1.370 .53-2.80$ & $0.650 .31-1.18$ & $1.100 .63-1.77$ & $0.840 .25-1.93$ & $1.010 .58-1.63$ \\
\hline Lung & $0.470 .18-1.13$ & $0.810 .60-1.10$ & $0.530 .29-0.88$ & $1.020 .31-2.33$ & $0.350 .11-0.80$ & $0.740 .59-0.94$ & $0.440 .22-0.80$ & $0.600 .36-0.95$ & $0.640 .41-0.97$ & $0.500 .22-1.01$ & $0.870 .56-1.29$ \\
\hline Breast & $1.551 .04-2.19$ & $0.890 .74-1.06$ & $0.840 .60-1.13$ & $1.230 .63-2.05$ & $0.760 .45-1.22$ & $0.880 .78-1.01$ & $0.830 .58-1.15$ & $0.860 .67-1.08$ & $1.040 .83-1.29$ & $0.540 .33-0.84$ & $1.190 .95-1.48$ \\
\hline Bladder & $1.930 .60-5.06$ & $1.250 .81-1.85$ & $0.620 .17-1.47$ & $0.870 .09-3.77$ & $0.580 .10-1.68$ & $0.940 .67-1.29$ & $1.810 .67-3.93$ & $1.450 .62-2.98$ & $1.220 .53-2.33$ & $0.760 .21-2.11$ & $1.030 .46-1.86$ \\
\hline Hematologic & $1.680 .96-2.80$ & $1.050 .87-1.25$ & $1.180 .75-1.81$ & $0.850 .24-2.02$ & $1.030 .56-1.79$ & $0.980 .83-1.15$ & $1.180 .75-1.76$ & $1.040 .75-1.42$ & $1.090 .80-1.43$ & $0.640 .36-1.06$ & $0.710 .51-0.98$ \\
\hline Total cancer* & $1.150 .96-1.37$ & 1.09 1.00-1.19 & $1.030 .90-1.17$ & $0.990 .76-1.28$ & $0.910 .71-1.15$ & $1.060 .99-1.13$ & $1.030 .87-1.21$ & $0.980 .87-1.11$ & $1.100 .98-1.24$ & $0.630 .49-0.80$ & $1.110 .99-1.23$ \\
\hline
\end{tabular}

RR comparing percentiles 5 and 95 of the deprivation index. Women, 11 cities of Spain, 1996-2003.

RR: Relative risk of mortality.

95\% Cl credibility interval. 
Table 4 Number of cases of cancer mortality and percentage of excess mortality under the assumption that deprivation of each area was the same as the average deprivation of the $10 \%$ of areas with the lowest deprivation

\begin{tabular}{|c|c|c|c|c|c|c|c|c|}
\hline \multirow{3}{*}{$\begin{array}{l}\text { Cities } \\
\text { Alicante }\end{array}$} & \multicolumn{4}{|c|}{ Men } & \multicolumn{4}{|c|}{ Women } \\
\hline & \multirow{2}{*}{$\begin{array}{r}\text { Number (total }=16.413 \text { ) } \\
481\end{array}$} & \multirow{2}{*}{$\begin{array}{r}\% \text { of excess } \\
15.57\end{array}$} & \multicolumn{2}{|c|}{$95 \% \mathrm{Cl}$} & \multirow{2}{*}{ Number $($ total $=1.142)$} & \multirow{2}{*}{$\begin{array}{r}\% \text { of excess } \\
5.61\end{array}$} & \multicolumn{2}{|c|}{$95 \% \mathrm{Cl}$} \\
\hline & & & 6.65 & 23.75 & & & -4.16 & 14.60 \\
\hline Barcelona & 3736 & 17.38 & 14.15 & 20.83 & 502 & 3.38 & -0.82 & 7.69 \\
\hline Bilbao & 695 & 13.17 & 7.79 & 15.56 & 38 & 1.13 & -6.31 & 8.09 \\
\hline Castellón & 83 & 5.18 & -8.53 & 16.92 & -8 & -1 & -17.65 & 14.20 \\
\hline Córdoba & 45 & 1.52 & -10.53 & 12.57 & -83 & -4.73 & -18.02 & 7.51 \\
\hline Madrid & 7099 & 19.49 & 17.07 & 21.98 & 621 & 2.54 & -0.89 & 6.05 \\
\hline Málaga & 778 & 17.79 & 10.73 & 24.29 & 29 & 1.01 & -8.83 & 9.79 \\
\hline Sevilla & 1161 & 16.31 & 10.81 & 21.53 & -48 & -1.03 & -7.14 & 5.23 \\
\hline Valencia & 1343 & 14.61 & 8.53 & 20.00 & 260 & 4.40 & -2.54 & 10.85 \\
\hline Vigo & -166 & -5.68 & -19.35 & 7.70 & -508 & -26.53 & -44.43 & -10.93 \\
\hline Zaragoza & 1158 & 15.52 & 9.63 & 21.06 & 231 & 4.95 & -1.39 & 11.05 \\
\hline
\end{tabular}

Men and women, 11 cities in Spain, 1996-2003.

$95 \% \mathrm{Cl}$ credibility interval.

\section{Cancer mortality inequalities in women}

Among women (table 3 ) the pattern of socioeconomic inequalities differs from that of men. For total cancer mortality, inequalities have only been found in Barcelona and Zaragoza, cities in which the proportions of deaths attributable to deprivation are $3.38 \%$ and $4.95 \%$ respectively. In Castellón and Vigo, where no inequalities were found in men, the relationships for women are inverse and significant, with Vigo presenting an RR $=0.63$ 95\%CI 0.49-0.80. Similarly, in Seville where men presented one of the highest levels of inequality, in the case of women the relation is inverse, although in this case not statistically significant.

Figure 1 and 2 present the distributions of socioeconomic deprivation and of cancer risk of mortality (smoothed SMR) among women in the same census tracts of the same cities as for men (Barcelona, Madrid, Seville, Cordoba and Vigo), and both the direct and inverse relationships, described above, may be seen. The case of Vigo stands out, where the majority of census tracts present this inverse relationship between deprivation and risk of mortality.

Stomach cancer mortality among women (table 3) presents significant inequalities in Barcelona $(R R=1.74$ 95\%CI 1.34-2.20), Madrid ( $\mathrm{RR}=1.51$ 95\%CI 1.26-1.77) and Valencia $(\mathrm{RR}=1.7195 \% \mathrm{CI} 1.11-2.54)$. There is an important and significant inverse inequality with respect to lung cancer, which may be observed in 6 of the 11 cities under study: Bilbao, Cordoba, Madrid, Malaga, Seville and Valencia. Significant inverse inequality may also be observed for colon cancer in Córdoba $(\mathrm{RR}=$ 0.48 95\%CI 0.24-0.84) and Vigo ( $R R=0.59$ 95\%CI 0.350.96). In the case of breast cancer, in general it presents an inverse relationship although this is only significant in Vigo ( $R R=0.5495 \% C I$ 0.33-0.84), while Alicante presents significant inequality, in the sense of higher levels of mortality in the more disadvantaged census tracts $(\mathrm{RR}=1.55$ 95\%CI 1.04-2.19). The inverse and significant relationship for hematological cancers in Zaragoza (RR $=0.7195 \%$ CI 0.51-0.98) also stands out. The excess

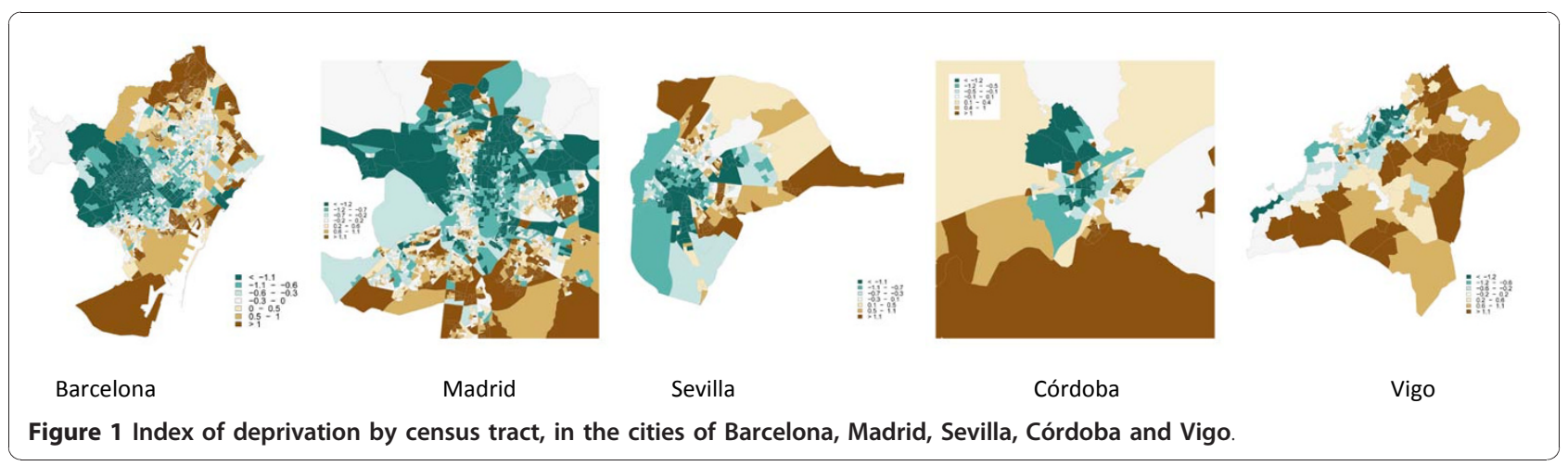




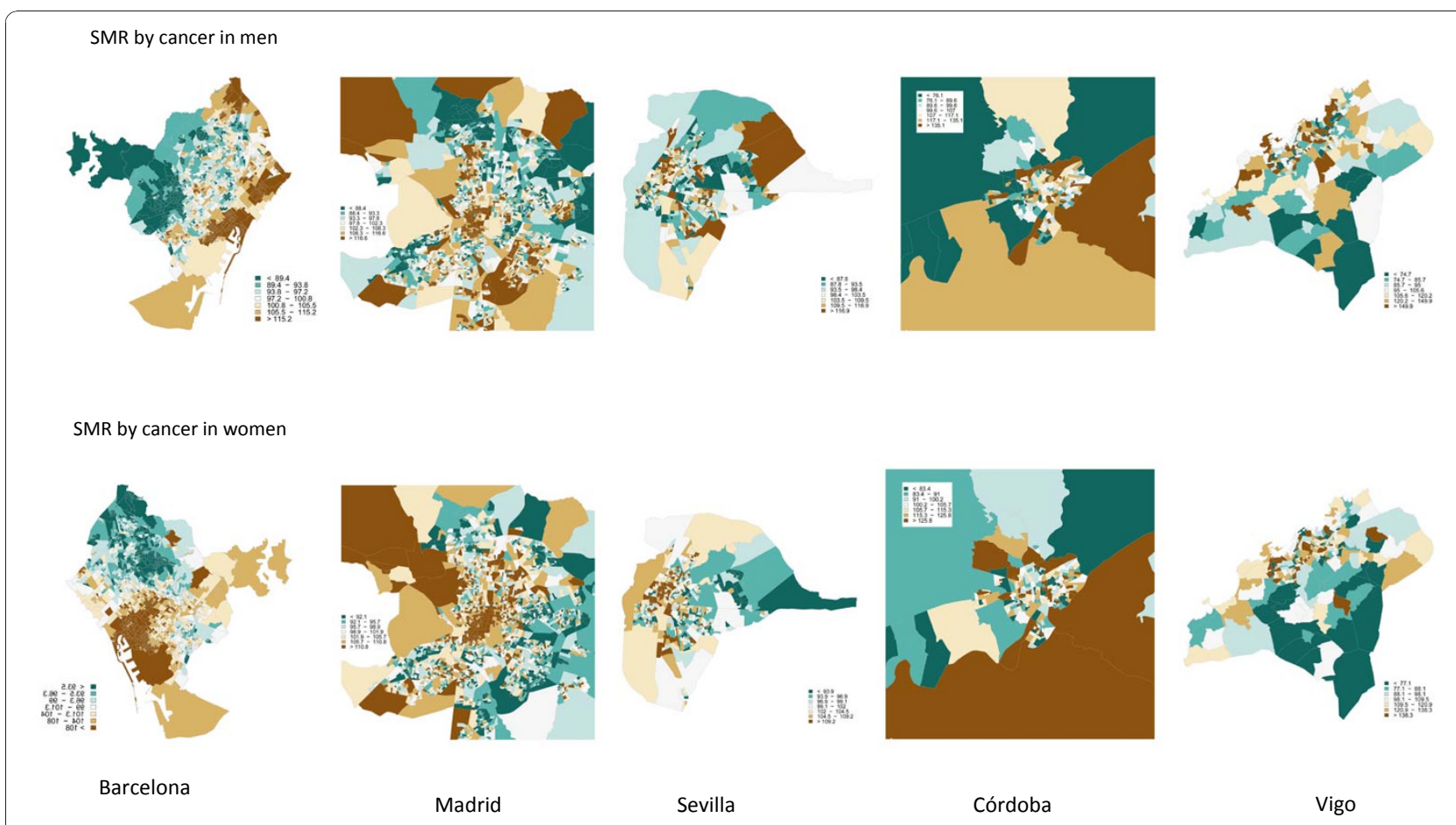

Figure 2 Cancer mortality (smoothed Standardized Mortality Ratios) by census tract in men (top) and women (bottom) in Barcelona, Madrid, Sevilla, Córdoba and Vigo.

number of cancer deaths due to socioeconomic deprivation was 1142 (table 4).

\section{Discussion}

The present study has detected, for the first time in Spanish cities, socioeconomic inequalities in total cancer mortality in men, whereas in women these inequalities disappear, and even there are cases of a pattern of an inverse relationship between area of residence socioeconomic deprivation and risk of mortality. The cities with the greatest inequalities are the country's largest cities, Barcelona and Madrid, but also Alicante and Seville. Moreover in the small cities, Castellón, Córdoba and Vigo, men present no inequalities, and women in Vigo present a significant inverse relationship. The pattern by cause of death among men showed that lung and larynx cancer had higher risk of mortality in areas with more socioeconomic deprivation in the majority of cites while among women lung cancer had an inverse relationship in six cities. The excess number of cancer deaths due to socioeconomic deprivation was 16,413 for men and 1142 for women.

\section{Interpretation of the results found}

The various relationships found between deprivation of the area of residence and cancer mortality among men and among women are partly due to the important presence of the most common cancers in these two groups. Thus, in men the most common cancers are also the ones presenting the highest levels of inequality. In the case of women, breast and lung cancer mortalities in general present an inverse relationship with socioeconomic deprivation, as has previously been reported in the comparison of various European cities [32].

The results of the present study are in accordance with those found in these same cities when studying mortality due to various other causes, apart from cancer [21] and in the case of Barcelona, the inequalities described are also observed when studying the trends in inequalities over recent years, and which have a stable tendency to decrease [33].

In order to understand the influence of inequalities on cancer mortality, we must determine, among other things, the behaviour of the population in regard to the known risk factors linked to these diseases. In consequence, we have to acknowledge that cancer is related to smoking in many types of cancer (lung, mouth and pharynx, larynx, oesophagus, bladder, stomach, pancreas, and liver, among others) and the cause of $30 \%$ of deaths due to cancer worldwide. The consumption of alcoholic beverages is also associated with cancers of the mouth, larynx, oesophagus, liver, colon, rectum and breast in women. Finally diet, mainly linked to stomach cancer and to a considerably lesser extent to colon, breast and 
prostate cancers [1]. Even so, and although the main risk factors are known, many other environmental exposures are still to be identified, and are difficult to study.

The evolution of smoking has been different for men and women, depending on social class. In Spain, smoking in women basically affects the generations born since 1950. In Europe, over the last 50 years, smoking began among men, then spread to women, from North to South, and from the privileged social classes to the more disadvantaged ones [34,35], and hence cancer mortality related to this risk factor evolves in the same sense. Thus, it is observed that among women, in most cities, mortality reflects the greater presence of smoking in women of the highest socioeconomic levels [36,37] as they began smoking earlier. Currently, smoking is more common in women of the less privileged social classes, as has happened among men, so that it is to be expected that within a few years mortality due to causes directly related to tobacco, such as lung cancer, will be higher in women of the disadvantaged social classes.

Other contributing factors are also present, such as those of an occupational nature, particularly in the inequalities observed in lung and larynx cancer, since these are the most common among men in manual occupations and therefore in the areas of greater socioeconomic deprivation. Specifically, in the case of larynx cancer, between $20 \%$ and $30 \%$ of the inequality can be attributed to occupational exposures [38,39].

Stomach cancer also presents inequalities, in both men and women. It continues to be one of the most common cancer types worldwide, although the fall in prevalence of the main known risk factor in the developed countries, the Helicobacter pylori bacterium, has led to a decline in its presence [1]. Other factors such as dietary habits differ between men and women regardless of social level [40] and of socioeconomic level indicator used $[41,42]$ which could partly explain the inequalities in stomach and colon cancers observed for men and for women. In the case of stomach cancer, it affects almost twice as many men compared to women, and this difference cannot be explained simply on the basis of different dietary habits. For this reason some authors suggest the possibility of an influence at hormonal level in the unequal presence of this cancer by gender $[43,44]$.

There are also other factors associated differently between men and women, and within these, between social classes, which interact and may contribute to explain the observed results. Thus, leisure time physical activity is more common in the more privileged social classes [45]. Alcohol consumption also presents a differential pattern due to the influence of various sociocultural factors [46], as also happens with smoking. Smoking on its own, for example, does not increase the risk of breast cancer, whereas alcohol does, and combined with smoking this risk becomes more impor$\operatorname{tant}$ [47].

All these highly inter-related health determinants cannot be isolated from the environments in which people live and work. Living in a city implies certain changes in lifestyle; in general urbanization has parallels with development, in the sense of having more opportunities, but these are not distributed equally over the city, and thus also for the social groups which live there. Thus, in all cities there are areas which could be considered healthy environments and others quite the contrary; moreover, in these areas the worst social and living conditions of the inhabitants are an obstacle to modify these conditions [48]. This implies the existence of risk factors characteristic of large urban nuclei and which must be taken into account, especially in ecological studies, such as for example atmospheric pollution or the worse job conditions of people living in more socioeconomically disadvantaged areas.

The important migratory movements occurring in cities all over the world, including Spain, mean there is a risk of generating important new pockets of poverty, apart from sociocultural alterations which affect the changes of aspect and personality of entire neighbourhoods, as is happening in certain areas of some Spanish cities [14]. It should be pointed out that although these changes have as yet had little effect on mortality, since the majority of the immigrant population is young, it is likely that this will change in the future.

\section{Limitations and strengths of the study}

One limitation of the present study is the fact of aggregating information over different years, since this prevents us from having information about time trends [49]. Another limitation, is the bias that can have this kind of study due the unmeasured geographic mobility of the population [50], although we assumed that during these years mobility was not very important. Furthermore, during the period studied there was a change in the system for coding causes of death, ICD-10 superseding ICD-9, although one study conducted in various Autonomous Communities of Spain showed that there were no important differences in the classification of the leading causes of death, cancer among them [51].

The main contribution of the present study is that it presents, for the first time, inequalities in cancer mortality in small areas of various Spanish cities. The fact of describing mortality in small areas means that we obtain clearer "snapshots" of the spatial distributions of cancer mortality and of deprivation.

\section{Conclusions and recommendations}

This study has described inequalities in cancer mortality in small areas of cities in Spain, not only relating this mortality 
with socioeconomic deprivation, but also calculating the excess mortality which may be attributed to such deprivation. This knowledge is particularly useful to determine which geographical areas in each city need intersectorial policies in order to promote a healthy environment [15,52].

\section{Note}

This paper forms part of the PhD dissertation of Rosa Puigpinós I Riera in the Doctoral Programme in Public Health, University of Barcelona.

\section{Acknowledgments/funding}

We would like to express our thanks to the MEDEA Working Group: Montse Calvo, Antonio Daponte, M. Felicitas Domínguez-Berjón, Santiago Esnaola, Ana Gandarillas, Gonzalo López-Abente, M Carmen Martos, Miguel Angel Martínez-Beneito, Agustín Montes-García, Imanol Montoya, Andreu Nolasco, M Isabel Pasarín, Maica Rodríguez-Sanz, Marc Sáez, Pablo SánchezVillegas.

This article was partially supported by Fondo de Investigaciones Ssanitarias (FIS) projects numbers PI042013, PI040041, PI040170, PI040069, PI042602 PI040388, PI040489, PI042098, PI041260, PI040399, PI081488 and by the CIBER en Epidemiología y Salud Pública (CIBERESP), Spain and by the program of "Intensificación de la Actividad Investigadora (Carme Borrell)" funded by the "Instituto de Salud Carlos III" and "Departament de Salut. Generalitat de Catalunya".

\section{Author details}

'Servei de Sistemes d'Informació Sanitaria, Agència de Salut Pública de Barcelona, Barcelona, Spain. ${ }^{2}$ CIBER Epidemiología y Salud Pública (CIBERESP), Parc de Recerca Biomédica de Barcelona, Barcelona, Spain. ${ }^{3}$ Departament de Salut Pública, Facultat de Medicina, Universitat de Barcelona, Barcelona, Spain. ${ }^{4}$ Universitat Pompeu Fabra, Barcelona, Spain. ${ }^{5}$ Estudios e investigación Sanitaria, Departamento de Sanidad y Consumo. Gobierno Vasco, VitoriaGasteiz, Spain. ${ }^{6}$ Observatorio de Salud y Medio Ambiente de Andalucía (OSMAN), Area de Salud Pública y Protección de la Salud, Escuela Andaluza de Salud Pública, Granada, Spain. ${ }^{7}$ Servicio de Informes de Salud y Estudios, Instituto de Salud Pública, Dirección General de Salud Pública y Alimentación, Consejería de Sanidad, Comunidad de Madrid. ${ }^{8}$ Servicio de Epidemiologia, Dirección General de Atención Primaria, Comunidad de Madrid. ${ }^{9}$ Area de Epidemiología Ambiental y Cáncer, Centro Nacional de Epidemiología, Madrid, Spain. ${ }^{10}$ Area de Desigualdades en Salud, Centro Superior de Investigación en Salud Pública de Valencia, Spain. ${ }^{11}$ Instituto Aragonés de Ciencias de la Salud, Aragón, Spain. ${ }^{12}$ Departamento de Medicina Preventiva e Saude Pública, Universidade de Santiago de Compostela, Spain. ${ }^{13}$ Unitat d'Investigació en Anàlisi de la Mortalitat i Estadística Sanitaria, Departament d'Infermeria Comunitària, Medecina Preventiva i Salut Pública i Història de la Ciencia, Universitat d'Alacant, Spain. ${ }^{14}$ Research Group on Statistics, Applied Economics and Health (GRECS), University of Girona, Spain.

\section{Authors' contributions}

$C B, R P R, A D, F D B, S E, A G, G L A, C M M, M A M B, A M M, A N, I M P, M S, P S V$ were all involved in designing the study. RPR wrote the first draft of the manuscript and bibliography review to which all authors subsequently contributed. MM, GS performed the statistical analysis and MG was involved in the elaboration of maps. MC, AD, FDB, SE, AG, CMM, MAMB, AMM, IM, AN, IMP, MRS, MS, PSV, CA were involved in collection of data and building the data bases. All authors made contribution to statistical analyses and interpretation of results, and revised the manuscript for important intellectual content. All authors read and approved the final manuscript.

\section{Competing interests}

The authors declare that they have no competing interests.

Received: 13 July 2010 Accepted: 13 January 2011

Published: 13 January 2011
References

1. World Cancer Report 2008: International Agency for Research on Cancer (IARC) Peter Boyle and Bernard Levin. Lyon 2008.

2. The global burden of disease:2004. World Health Organization. Geneva; 2008

3. Instituto de Investigación Sanitaria: Mortalidad por cáncer, por enfermedad isquémica del corazón, por enfermedades cerebrovasculares y por diabetes mellitus en España. Madrid: Ministerio de Sanidad y Consumo; 2009.

4. Ferlay J, Autier P, Boniol M, Heanue M, Colombet M, Boyle P: Estimates of the cancer incidence and mortality in Europe in 2006. An Oncol 2007, 18:581-91.

5. Bosetti C, Bertuccio P, Levi F, Lucchini F, Negri E, La Vecchia C: Cancer mortality in the European Union, 1970-2003, with a joinpoint analysis. An Oncol 2008, 19:631-40.

6. Mackenbach JP, Stirbu I, Roskam AJ, Schaap MM, Menvielle G, Leinsalu M, Kunst AE, European Union Working Group on Socioeconomic Inequalities in Health: Inequalities in Health. Socieoconomic inequalities in Health in 22 european Countries. N Engl J Med 2008, 23:2468-81.

7. Gispert R, Clèries R, Puigdefàbregues A, Freitas L, Esteban L, Ribes J: Tendencias de la mortalidad por cáncer en Catalunya, 1985-2004. Med Clin (Barc) 2008, 131:25-31.

8. Fernández $\mathrm{E}$, Borrell $\mathrm{C}$ : Cancer mortality by educational level in the city of Barcelona. Br J Cancer 1999, 79:684-89.

9. Kamel Boulos DN, Ghali RR, Ibrahim SM, Kamel Boulos MN, Abdel Malik Ph: An eight-year snapshot of geospatial cancer research (2002-2009): clinico-epidemiological and methodological findings and trends. Med Oncol 2010.

10. Benach J, Yasui Y, Borrell C, Sáez M, Pasarin MI: Material deprivation and leading causes of death by gender: evidence from a nationwide small area study. J Epidemiol Community Health 2001, 55:239-45.

11. Krieger N: Ladders, pyramids and champagne: the iconography of health inequities. J Epidemiol Community Health 2008, 62:1098-104.

12. Navarro V, Muntaner C, Borrell C, Benach J, Quiroga A, Rodríguez-Sanz M, Vergés N, Pasarín Ml: Politics and health outcomes. Lancet 2006, 16:1033-1037.

13. Espelt A, Borrell C, Rodríguez-Sanz M, Muntaner C, Pasarín Ml, Benach J Schaap $M$, Kunst AE, Navarro $V$ : Inequalities in health by social class dimensions in European countries of different political traditions. Int J Epidemiol 2009, 37:1095-1105.

14. La salut de la població immigrant de Barcelona. Barcelona: Agència de Salut Pública de Barcelona; 2008.

15. Our cities, our health, our future: acting on social determinatns for health equity in urban settings. Report of the Knowledge Network on Urban Settings, WHO Commission on Social Determinants of Health. Health Urbanization; 2007

16. Borrell C, Pasarín MI: Inequalities in health and urban areas. Gac Sanit 2004, 18:1-4

17. Ruiz-Ramos M, Escolar A, Sánchez J, Garrucho G: Inequalities in mortality in Seville (Spain). Gac Sanit 2004, 18:16-23.

18. Saurina C, Saez M, Marcos-Gragera R, Barceló MA, Renart G, Martos C: Effects of deprivation on the geographical variability of larynx cancer incidence in men, Girona (Spain) 1994-2004. Cancer Epidemiology 2010, 34:109-115.

19. Benach J, Yasui Y: Geographical patterns of excess mortlity in Spain explained by two indices of deprivation. J Epidemiol Community Health 1999, 53:423-431.

20. Krieger N: Defining and investigating social disparities in cancer: critical issues. Cancer Causes Control 2005, 16:5-14.

21. Borrell C, Marí-Dell'olmo M, Serral G, Martínez-Beneito M, Gotsens M, MEDEA Members: Inequalities in mortality in small areas of eleven Spanish cities (the multicenter MEDEA project). Health Place 2010, 16:703-711.

22. Domínguez-Berión MF, Borrell C, Cano-Serral G, Esnaola S, Nolasco A, Pasarín Ml, Ramis R, Saurina C, Escolar-Pujolar A: Constructing a deprivation index based on census data in large Spanish cities(the MEDEA project). Gac Sanit 2008, 22:179-87.

23. Besag J, York J, Mollie A: Bayesian image restoration, with two applications in spatial statistics. Annals Institute Stat Mathematics 1991, 43:1-59.

24. Gelman A: Prior distributions for variance parameters in hierarchical models. Bayesian Analysis 2006, 3:515-33. 
25. Best N, Richerdson S, Thomson A: A comparison of Bayesian spatial models for disease mapping. Stat Methods Med Res 2005, 14:35-9.

26. Barceló MA, Saez M, Cano-Serral G, Martínez-Beneito MA, Martínez JM, Borrell C, Ocaña-Riola R, Montoya I, Calvo M, López-Abente G, RodríguezSanz M, Toro S, Alcalá JT, Saurina C, Sánchez-Villegas P, Figueiras A: Methods to smooth mortality indicators: application to analysis of inequalities in mortality in Spanish cities [the MEDEA Project]. Gac Sanit 2008, 22:596-608.

27. Lunn D, Thomas A, Best N, Spiegelhalter D: WinBUGS, a Bayesian modelling framework: concepts, structure and extensibility. Statistics Comput 2000, 10:325-37.

28. R Development Core Team. R: A language and environment for statistical computing. R Foundation for Statistical Computing, Vienna, Austria; 2009 [http://www.R-project.org], ISBN 3-900051-07-0.

29. Brooks S, Gelman A: Alternatives methods for monitorin convergence of iterative simulations. J Comput Graph Stat 1998, 7:434-55.

30. Montse Vergara Duarte: Assessing "extreme amenable mortality" in Spain: A nationally-based time trend small area analysis (1987-2004). Vegara M. Estrategias de clasificación y aplicación al análisis de la desigualdad geográfica en España., Universitat Pompeu Fabra, Barcelona; 2009, 133-153, [doctoral dissertation].

31. Kunkel SR, Atchley RC: Why gender matters: being female is not the same as not being male. Am J Prev Med 1996, 12:294-6.

32. Menvielle G, Kunst AE, Stirbu I, Strand BH, Borrell C, Regidor E, Leclerc A, Esnaola S, Bopp M, Lundberg O, Artnik B, Costa G, Deboosere P, Martikainen P, Mackenbach JP: Educational differences in cancer mortality among women and men: a gender pattern that differs across Europe. British J Cancer 2008, 98:1012-19.

33. Puigpinós R, Borrell C, Antunes JL, Azlor E, Pasarín Ml, Serral G, PonsVigués M, Rodríguez-Sanz M, Fernández E: Trends in socioeconomic inequalities in cancer mortality in Barcelona: 1992-3003. BMC Public Health 2009, 9:35.

34. Huisman $M$, Kunst $A E$, Mackenbach JP: Educational inequalities in smoking among men and women aged 16 years and older in 11 european countries. Tobacco Control 2005, 14:106-13.

35. Mackenbach JP, Huisman M, Andersen O, Bopp M, Borgan JK, Borrell C, Costa G, Deboosere P, Donkin A, Gadeyne S, Minder C, Regidor E, Spadea T, Valkonen T, Kunst AE: Inequalities in lung cancer mortality by the educational level in 10 European populations. Eur J Cancer 2004, 40:126-35.

36. Regidor E, Gutierrez-Fisac $\lrcorner$, Calle ME, Navarro P, Domínguez V: Trends in cigarette smoking in Spain by social class. Prev Med 2001, 33:241-8.

37. Giskes K, Kunst AE, Benach J, Borrell C, Costa G, Dahl E, Dalstra JA Federico B, Helmert U, Judge K, Lahelma E, Moussa K, Ostergren PO, Platt S, Prattala R, Rasmussen NK, Mackenbach JP: Trends in smoking behaviour between 1985 and 2000 in nine European countries by education. J Epidemiol Community Health 2005, 59:395-401.

38. Menvielle G, Luce D, Goldberg P, Leclerc A: Smoking, alcohol drinking, occupational exposures and social inequalities in hypopharungeal and laryngeal cancer. Int J Epidemiol 2004, 33:799-806.

39. Menvielle $G$, Boshuizen $H$, Kunst AE, Dalton SO, Vineis P, Bergmann MM Hermann S, Ferrari P, Raaschou-Nielsen O, Tiønneland A, Kaaks R, Linseisen J, Kosti M, Trichopoulou A, Dilis V, Palli D, Krogh V, Panico S, Tumino R, Büchner FL, van Gils CH, Peeters PH, Braaten T, Gram IT, Lund E, Rodriguez L, Agudo A, Sánchez MJ, Tormo MJ, Ardanaz E, et al: The role of smoking and diet in explaining educational inequalities in lung cancer incidence. J Nat Cancer Institute 2009, 101:321-30.

40. Hendrie GA, Coveney J, Cox D: Exploring nutrition knowledge and the demographic variation in knowledge levels in a Australian community sample. Public Health Nutrition 2008, 11:1365-71.

41. Ward H, Tarasuk V, Mendelson R: Socioeconomic patterns of obesity in Canada: modeling the role of health behaviour. Appl Physiol Nutr Metab 2007, 32:206-16.

42. Wardle J, Waller J, Jarvis M: Sex differences in the association of socioeconomic status with obesity. Am J Pub Health 2002, 92:1299-304.

43. Chandanos E, Lagergren J: Oestrogen and the enigmatic male predominance of gastric cancer. Eur J Cancer 2008, 44:2397-403.

44. Frise S, Kreiger N, Gallinger S, Tomlinson G, Cotterchio M: Menstrual and reproductive risk factors and risk for gastric adenocarcinoma in women: findings from the Canadian National Enhanced Cancer Surveillance System. AEP 2006, 16:908-916.
45. Dowler E: Inequalities in diet and physical activity in Europe. Public Health Nutrition 2001, 4:701-09.

46. Bobo JK, Husten C: Sociocultural influences on smoking and drinking. Alcohol Res Health 2000, 24:225-32.

47. Collaborative Group on Hormonal Factors in breast cancer: Alcohol, tobacco and breast cancer-collaborative reanalysis of individual data from 53 epidemiological studies, including 585151 women with breast cancer and 95067 women without the disease. British J Cancer 2002, 87:1234-45.

48. Fleischer NL, Diez Roux AV, Alazraqui M, Spinelli $\mathrm{H}$ : Social patterning of chronic disease risk factors in a Latin American City. J Urban Health 2008 85:923-37

49. Ocaña-Riola R: The misuse of count data aggregated over time for disease mapping. Statistics in Medicine 2006, 26:4489-4504.

50. Ocaña-Riola R, Fernández-Ajuria A, Mayoral-Cortés JM, Toro-Cárdenas S, Sánchez-Cantalejo C: Uncontrolled migrations as a cause of inequality in health and mortality in small-area studies. Epidemiology 2009, 20:411-8.

51. Cano-Serral G, Pérez G, Borrell C, Grupo COMPARA: Comparability beteen ICD-9 and ICD-10 for the leading causes of death in Spain. Rev Epidemiol Santé Pub 2006, 54:355-65.

52. Cities and Public Health Crises. Report of the International consultation. World Health Organization; 2009.

doi:10.1186/1476-072X-10-6

Cite this article as: Puigpinós-Riera et al:: Cancer mortality inequalities in urban areas: a Bayesian small area analysis in Spanish cities. International Journal of Health Geographics 2011 10:6.

\section{Submit your next manuscript to BioMed Central and take full advantage of:}

- Convenient online submission

- Thorough peer review

- No space constraints or color figure charges

- Immediate publication on acceptance

- Inclusion in PubMed, CAS, Scopus and Google Scholar

- Research which is freely available for redistribution

Submit your manuscript at www.biomedcentral.com/submit
C) Biomed Central 